Please note that this is a Pre-print of a manuscript in press to appear in the Journal of Group Processes and Intergroup Relations

\title{
The Great Replacement Conspiracy: How the Perceived Ousting of Whites Can Evoke Violent Extremism and Islamophobia
}

\author{
Milan Obaidi ${ }^{1,2}$, Jonas Kunst ${ }^{1,2}$, Simon Ozer ${ }^{3}$, Sasha Y. Kimel ${ }^{4}$ \\ ${ }^{1}$ Department of Psychology, Oslo University \\ ${ }^{2}$ Center for Research on Extremism, Oslo University \\ ${ }^{3}$ Department of Psychology and Behavioral Sciences, Aarhus University \\ ${ }^{4}$ Department of Psychology, California State University
}

\begin{abstract}
Author Note
Milan Obaidi, Department of Psychology and Center for Research on Extremism, Oslo University; Jonas Kunst, Department of Psychology and Center for Research on Extremism, Oslo University; Simon Ozer, Department of Psychology and Behavioral Sciences, Aarhus University and Sasha Y. Kimel Department of Psychology, California State University San Marcos

The research was supported by grants the Sasakawa Young Leader's Fellowship to Milan Obaidi.

Address correspondence to Milan Obaidi, Department of Psychology, University of Oslo P. O. Box 1094 Blindern, N-0322 Oslo, Norway Oslo, Norway. E-mail: Milanob@psykologi.uio.no

The data that support the findings of this paper are available from the corresponding author upon reasonable request.
\end{abstract}




\begin{abstract}
Increased immigration and demographic changes have not only resulted in political pushback, but also in violent attacks against immigrants. Several recent terrorist attacks committed by White supremacists invoke rhetoric around a deliberate attempt to make Whites extinct and replace them with non-Western immigrants. Yet, while it is widely acknowledged among extremism researchers that this perception of orchestrated extinction or replacement has tremendous potential to lead to violent extremism, its consequences have not yet been directly examined. Using the Scandinavian context (e.g., Denmark and Norway), in two correlational studies and one experiment, we provide evidence that this perception is associated with the persecution of Muslims, violent intentions, and Islamophobia. Further, we demonstrate that these associations are mediated by symbolic threats. Conspiracy beliefs that one's group is being replaced seems to drive hostile intergroup attitudes. We discuss the societal implications of this finding (i.e., generating fear, polarization and hostile public opinion towards immigrants).

Key words: Great Replacement conspiracy, majority-minority society, violent extremism, Islamophobia, threat perceptions, radicalization
\end{abstract}


THE GREAT REPLACEMENT CONSPIRACY AND ANTI-MUSLIM RESENTMENT

\section{The Great Replacement Conspiracy: How the Perceived Ousting of Whites Can Evoke Violent Extremism and Islamophobia}

"Most of all show the invaders that our lands will never be their lands, our homelands are our own and that, as long as a white man still lives, they will NEVER conquer our lands and they will never replace our people." (Brenton Harrison Tarrant the Christchurch terrorist, 2019).

'Europe is no longer Europe, it is 'Eurabia', a colony of Islam, where the Islamic invasion does not proceed only in a physical sense, but also in a mental and cultural sense." (Oriana Fallaci, Varadarajan, 2005).

On Friday March 15, 2019, Brenton Harrison Tarrant, entered two mosques in Christchurch, New Zealand. There, he gunned down over 50 Muslim worshipers. The morning before the massacre, Tarrant released a manifesto entitled the "Great Replacement." In it, he accused liberal politicians of deliberately engineering the extinction or replacement of White Westerners through mass immigration of non-Whites. Rooted in Nazi-era writings, this conspiracy, which also argues that a "race war" is inevitable (Williams, 2017) has recently been repurposed by the far-right (Serwer, 2019). Indeed, it gained prominence in 2011 with the publication of "Le Grand Replacement" by Renaud Camus - a book that has been argued to have played a vital role in Tarrant's radicalization (Davey \& Ebner, 2019). Importantly, this conspiracy has had world-wide reach. For example, the 2019 Walmart El Paso shooter who killed 20 people and wounded 26 others near the US-Mexican border wrote in his manifesto that "in general, I 
THE GREAT REPLACEMENT CONSPIRACY AND ANTI-MUSLIM RESENTMENT

support the Christchurch shooter and his manifesto. This attack is a response to the

Hispanic invasion of Texas" (Arango et al., 2019). Likewise, the recent shooters in the U.S. including in Charleston, Pittsburgh, Poway as well as in Munich, Germany relied on similar language and justifications (Chavez et al., 2018; Miller, 2019).

Examining whether and how the prevalence of extreme anti-immigrant attitudes is impacted by rhetoric adopting aspects of the "Great Replacement" conspiracy (i.e., argument that White populations are being replaced at an ethnic and cultural level through mass migration, Davey \& Ebner, 2019), is of great theoretical and practical interest for several reasons. First, such ideas are no longer limited to the outer fringes of the public discourse as the proponents of this conspiracy can now be found in mainstream politics, the media, and the general public (Bellware, 2019). For example, recently leaked emails show that the former White House senior advisor Stephen Miller promoting farright extremist, White nationalist ideas, and anti-immigrant rhetoric through the conservative website Breitbart. Importantly too, he appeared fixated with the prospect of a "White genocide" (i.e., a conspiracy theory associated with white supremacists propagating that the white race is dying due to growing non-white populations, Bellware, 2019). Second, in recent years, extreme-right parties have sought to leverage the majority group's fear of replacement. For instance, the conspiracy has been fundamental in fueling "nativist" campaigns like the one by Alexander Gauland, co-leader of the far-right Alternative for Germany party who, before the 2017 German election, made "The Great Replacement" the title of a news release (Bennhold, 2019). Third, although considerable research has examined the impact of the perceived size of outgroups on one's hostility towards that same groups (e.g., Alba et al., 2005; Craig \& Richeson, 2014a, 2014b; 
THE GREAT REPLACEMENT CONSPIRACY AND ANTI-MUSLIM RESENTMENT

Danbold \& Huo, 2015; Outten et al., 2012), it appears that the specific impact of perceiving that there is a planned attempt to replace one's group with another has not yet been examined. Importantly, the "Great Replacement" is fundamentally distinct. Whereas demographic changes and outgroup size are linked to concerns about loss of a privileged majority status and disruption of the existing social hierarchy (Mutz, 2018), the replacement conspiracy theory taps onto the perception of White people are facing existential decline - even extinction — because of the planned proliferation of immigration. Finally, research on how perceived demographic shifts impact violent extremism specifically (i.e., " a violent type of mobilization that aims to elevate the status of one group, while excluding or dominating its 'others' based on markers, such as gender, religion, culture and ethnicity"; Bak et al., 2019, p. 8) are largely missing. Thus, understanding the implications of this conspiracy is of urgent societal and theoretical importance.

\section{The "Great Replacement" and Violent Extremism}

In recent years, the "Great Replacement" conspiracy has not only received prominence among right-wing extremists but also found a foothold among right-wing populist political parties in Europe. For example, while evoking anti-Muslim and immigrant sentiment, such ideas have been espoused by the former leader of the Danish People's party (Pia Kjærsgaard ), the prime minister of Hungary (Viktor Orbán), the Italian interior minister (Matteo Salvini), and the leader of the far-right Rassemblement National (Marine Le Pen; Alduy, 2017; Kingsley, 2019; Kjærsgaard, 2020).Various conservative intellectuals and far-right organizations have also utilized language that stokes fear about the decline of the "White race" and "White identity." For instance, in an 
THE GREAT REPLACEMENT CONSPIRACY AND ANTI-MUSLIM RESENTMENT

interview in the Wall Street Journal in 2005, Mark Steyn, a prominent proponent of Eurabia (i.e., a term coined to describe an alleged Islamization and Arabization of Europe), claimed that by the year 2025 "Europe will be 40 percent Muslim and much of what we loosely call the Western world will not survive this century..." (Steyn, 2005, 2006). Meanwhile, anti-Muslim organizations such as the German PEGIDAmovement and the European White-nativist movement Generation Identity (GI) have espoused similar views. For example, GI — one of Europe's fastest growing farright movements that advocates for an ethnically and culturally homogenous Europeportrays immigrants as invaders while playing a prominent role in promoting, popularizing and disseminating the "Great Replacement" conspiracy (Cox \& Meisel, 2018; Feder \& Maplestone, 2019).

Although scholars have dismissed the demographic projections propagated by the “Great Replacement” as erroneous and non-scientific (see Alba, 2018; Alba et al., 2005), some warn that this conspiracy may have tremendous potential to lead to violent extremism (see Davey \& Ebner, 2019). For instance, according to Peter Neumann, director of the International Center for the Study of Radicalization at King's College in London, “... they [the GI] promote an idea that is taken by some people to justify violence. It is not directly responsible for the violence - but it enables it" (Neumann, cited in Bennhold, 2019). Moreover, drawing on the "3N model" of radicalization (Belanger et al., 2019), the Great Replacement conspiracy is likely to lead to violence by way of three factors: need (i.e., one's desire for significance), narrative (i.e., an ideological framework that provides moral justification), and network (i.e., the presence of others who share similar views). More specifically, when White's need for 
THE GREAT REPLACEMENT CONSPIRACY AND ANTI-MUSLIM RESENTMENT

significance is lost, such individuals may be more likely to believe the narrative that violence is an acceptable way to restore this loss and want to join a network of likeminded individuals (e.g., right-wing extremists).

\section{The Relationship Between Outgroup Size and Outgroup Negativity}

Increasing racial and ethnic diversity has triggered a sense of cultural loss or threat among Whites which, in turn, may precipitate this group's animosities towards other racial and ethnic groups (Craig \& Richeson, 2014a, 2014b; Danbold \& Huo, 2015; Jardina, 2019). Whereas it has been already demonstrated that both the perceived and actual size of a minority group is associated with outgroup prejudice (e.g., Allport, 1954; Blalock, 1967), within the European context, research suggests that it is specifically the perceived size of the group that predicts negativity toward the foreign population (Strabac, 2011; see also Krueger \& Pischke, 1997). Such findings are supported by several additional studies carried out in the European context. More specifically, these studies found a positive relationship between the relative size of outgroups and different manifestations of derogations against them (e.g., Schlueter \& Scheepers, 2010). For instance, the perceived relative size of a minority group was associated with ethnic exclusionary practices and strict immigration policies among majority members (Gorodzeisky \& Semyonov, 2009), a general dislike and negative behavioral intentions toward outgroups (i.e., not buying a car from an immigrant; Schlueter et al., 2008), opposition to civil rights for legal migrants (Sheepers et al., 2002), support for racial segregation (Card et al., 2008), a decrease in prosocial behavior (e.g., donations; Adida et al., 2016), support for far-right and extremist voting (Steinmayr, 2018; Vertier et al., 2018; Dinas et al., 2019) as well as anti-foreign (Semyonov et al., 2006), anti-immigrant 
THE GREAT REPLACEMENT CONSPIRACY AND ANTI-MUSLIM RESENTMENT

(Schneider, 2008), and anti-Muslim attitudes (Savelkoul et al., 2010). Further, a recent natural experiment showed that mere exposure to a large number of refugees makes the autochthonous population (i.e., in this case, the native Greeks) more hostile toward refugees, immigrants, and Muslim minorities (Hangartner et al., 2019). Yet, despite considerable research linking outgroup size to outgroup bias in a European context, research linking this to extremism specifically is limited. As far as we are aware of, the only study to examine this used data from various terrorism databases and found that the number of domestic right-wing terrorist attacks in a country was related to increased immigration flows, yet only in terms of non-European immigration (McAlexander, 2019). Nevertheless, this study did not directly examine the link between perceived replacement and anti-immigrant resentment. Further, the study was based on secondary data and as such it cannot establish causality, nor does it rule out spurious associations and alternative explanations.

Outside the European context, experimental studies and nationally representative samples (e.g., General Social Surveys in North America) have also demonstrated a link between the perceived numerical size of minorities and various outcomes. More specifically, it has been linked to support for conservative ideologies (Craig \& Richeson, 2014a), the Tea Party (Willer et al., 2016), far-right political candidates (Mutz, 2018), and anti-Black and anti-Hispanic attitudes (Alba et al., 2005). Furthermore, research demonstrated a link between the level of hostility toward minorities (e.g., Hispanics) and recent increase in migration of minority groups (Green et al., 1998; Lyons, 2008; Stacey et al., 2011). This is in line with newer findings illustrating that the dominant groups (e.g., White men) become less tolerant (Danbold \& Huo, 2015), and express higher 
THE GREAT REPLACEMENT CONSPIRACY AND ANTI-MUSLIM RESENTMENT

degrees of anger and fear of racial minorities when they are exposed to demographic projections suggesting that they will become a numerical minority (Outten et al., 2012). For instance, Whites report higher levels of prototypicality threat when they are exposed to information about their group's numerical decline leading to a rise in prejudice and hostility toward immigrants and racial minorities (Danbold \& Huo, 2017).

Taken together, there is robust evidence in both European and non-European contexts that people develop outgroup bias toward groups that are perceived to be growing in size. However, research has yet to directly test whether extreme antiimmigrant resentment is rooted in a belief that one's group is being replaced or may become extinct specifically. Moreover, despite the anecdotal associations between the discourse of the "Great Replacement" conspiracy and extremism (i.e., the rise of the antiimmigrant far right and neo-Nazi political organizations and far-right violence), to the best of our knowledge, empirical studies of this link are lacking. Furthermore, the association with intergroup hostility more broadly (e.g., Islamophobia) also appears to be a neglected area of research.

\section{The Potential Mediating Role of Symbolic and Realistic Threats}

Several scholars have proposed that the impending racial demographic change associated with out-group negativity and anti-minority attitudes (e.g., Blalock 1967; Craig \& Richeson, 2017; Craig et al., 2018; Danbold \& Huo, 2015; Schlueter \& Scheepers, 2010) is mediated by perceived threat to the economic, social, and cultural standing of the dominant group (Craig \& Richeson, 2014a, 2017). This suggests that majority group members not only use the relative group size to make inferences about their group's loss of power and hierarchical status but also see the demographic changes 
THE GREAT REPLACEMENT CONSPIRACY AND ANTI-MUSLIM RESENTMENT

as threat to their socio-economic and cultural standing in society. Indeed, members of majority groups often perceive the growing number of minorities as either symbolic threats (i.e., to a group's culture, norms, values, religion, and identity; Blinder, 2013; Semyonov et al., 2006) or realistic threats (e.g., to a group's physical and material welfare; Pew Research Center, 2013). Through intercultural interactions — such as international immigration - fear-driven and defensive reactions can emerge in relation to cultural mixing and the experience of cultural contamination (Torelli et al., 2011). In relation to this, perceived symbolic and realistic threats are significant as they can have largely destructive effects on such intergroup relations by activating negative attitudes and behavior addressed toward outgroup members (Stephan \& Stephan, 1993). Indeed, the predictive power of symbolic and realistic threat perceptions for outgroup hostility and aggression has been establish by a long line of research (Bueno de Mesquita, 2007). For instance, the anticipated decreasing gap in racial demographics between majority and minority groups in the U.S. led to threat perceptions among White Americans, resulting in negative racial attitudes and emotions (Craig \& Richeson, 2014b; Myers \& Levy, 2018; Outten et al., 2012). Relevant to the present paper, various studies document that the relationship between outgroup size and outgroup negativity is mainly mediated by perceptions of threatened group interests (Craig \& Richeson, 2014a, 2014b, 2017; Outten et al., 2012; Quillian, 1995; Schneider, 2008; Schlueter \& Scheepers, 2010). More specifically, previous research has shown that the impending "majority-minority" shift can trigger more cultural threats (Craig \& Richeson, 2017b; Danbold \& Huo, 2015).

Research also supports the link between symbolic and realistic threat perceptions and endorsement of violence specifically (Obaidi et al., 2018a; Ozer et al., 2020). 
However, the perceived size of an outgroup has been shown to be associated with realistic threats to a lesser degree than conflict over values and cultural issues (i.e., symbolic), which in turn may primarily lead to negative outgroup attitudes (Schneider, 2008; McAlexander, 2019; Piazza, 2017). Crucially, recent correlational evidence suggests that symbolic threats might rally support for outgroup violence to a greater extent than realistic threats (Obaidi et al. 2018a). This research is also in line with the literature on immigrant exclusion, showing that immigrant exclusion is driven primarily by symbolic threat perceptions rather than realistic threat perceptions (Bansak et al., 2016; Hainmueller \& Hopkins, 2014). Hence, in the current paper we predicted that the perceived demographic increase of immigrants and Muslims, in particular as propagated by the "Great Replacement" conspiracy, would be more strongly associated with symbolic (rather than realistic) threat perceptions and this, in turn, would be related to extreme types of outgroup hostility (e.g., violence).

\section{The Present Research}

To the best of our knowledge, the present set of studies are the first to investigate the relationship between perceived replacement of the White autochthonous population and outgroup negativity of any kind. All studies were conducted in the Scandinavian nations of Denmark and Norway as both are experiencing an increase in anti-Muslim and anti-immigrant sentiment, and "Great Replacement” rhetoric (Bilefsky, 2006; Lange, 2016; Pedersen, 2019). For instance, Denmark is well-known for the Muhammad caricature controversy published by the newspaper Jyllands-Posten, which was meant to be a response to the perceived Islamization of Denmark and its threat to Danish cultural norms (Hervik, 2012). Further, in Denmark, politicians, the media and the public have - 
THE GREAT REPLACEMENT CONSPIRACY AND ANTI-MUSLIM RESENTMENT

for a long time - adopted anti-Muslim and anti-immigration rhetoric, which closely mirrors the language employed by the proponents of the "Great Replacement" conspiracy (Bilefsky, 2006; Pedersen, 2019). It has been argued that this rhetoric has fueled hostile attitudes against the Muslim population to an extent where $28 \%$ of all ethnic Danes fully or partially support the expulsion of Muslims (Reiermann \& Andersen, 2019).

Similarly, in Norway, left-wing youth and governmental facilities were the targets of a terrorist attack committed by the White supremacist Anders Behring Breivik who justified his killings by referring to a perceived Islamization of Norway and whose manifesto heavily relied on the "Great Replacement" conspiracy (Fekete, 2012). Many public figures and politicians in Norway have also propagated this trend. For instance, a member of the right-wing Progress Party in Norway, Per-Willy Amundsen, warned of a "replacement of the population" (Lange, 2016). Against this background, Denmark and Norway were considered ideal European contexts to conduct our studies in.

Conducted in Denmark, studies 1 and 2 examined our hypotheses using a correlational design and measures of both general (e.g., Islamophobia) and extreme negative attitudes -- violent behavioral intentions towards outgroups (i.e., willingness to use violence to defend one's group; Obaidi et al., 2018a) and support for the violent persecution of Muslim (i.e., willingness to participate in the socially sanctioned persecution of Muslims, Altemeyer, 1996) while testing, in line with previous research, whether symbolic versus realistic threats would mediate this relationship (Bansak et al., 2016; Hainmueller \& Hopkins, 2014; Obaidi et al., 2018b; Raiya et al., 2008). Conducted in Norway, Study 3 manipulated perceived replacement and examined its causal effect on Islamophobia specifically (i.e., the fear of, and indiscriminate negative 
THE GREAT REPLACEMENT CONSPIRACY AND ANTI-MUSLIM RESENTMENT

attitudes, emotions and hostility toward Muslims and the Islamic faith; Jupskås and Leidig, 2020; Lee et al., 2009) via symbolic and realistic threats.

\section{Study 1}

Study 1 examined the relationship between perceived replacement of the White autochthonous population (e.g., ethnic Danes) and outgroup negativity (e.g., Muslim persecution, violent intentions, and Islamophobia) while testing whether symbolic rather than realistic threats would mediate this relationship.

\section{Method}

\section{Participants and procedure}

Following ethic's board stipulations for this and the remaining studies participants provided consent, were debriefed, and could also decline responding to any measure. A total of 162 White Danish participants $\left(M_{\mathrm{age}}=29.45, S D_{\mathrm{age}}=14.72\right.$; Age range: $18-70$; $50.6 \%$ females) were recruited through snowball sampling on Facebook and university mailing lists by, with the permission of group administrators, individually inviting each person to participate in the study and posting the survey on Facebook walls twice a week. A wide range of groups that discussed politics, immigration, and religion as well as those that focused on the university or discussed art, film, music, and culture were targeted. Based on previous studies among autochthonous Danes testing a similar model (see Obaidi et al., 2018a), we aimed to recruit 150 participants to have enough power to test the mediation model proposed in the current study. All participation was voluntary and participants received a gift card of 30DKK (\$5 USD) to an online fast-food chain for their participation. Of the total sample, $27.2 \%$ were enrolled in university studies, $19.1 \%$ had a bachelor's degree, $19.1 \%$ had a post-graduate degree, $16.1 \%$ had completed high 
school and $0.6 \%$ were enrolled in high school. Moreover, $50 \%$ identified as being middle class, $21 \%$ as being upper middle class, $9.9 \%$ as being working class, and $1.2 \%$ as being upper class ${ }^{1}$.

\section{Measures}

For this and all remaining studies, an overview of the measures and their full items can be found in the supplementary online materials (SOM). The survey was administered in the local languages (i.e., Danish in Denmark and Norwegian in Norway). All items were translated into Danish and Norwegian by the first and second authors, and to directly assess the accuracy of the translation, all items subsequently were backtranslated into English by two research assistants. Unless otherwise stated, all items were rated on 7-point Likert scales ranging from 1 (totally disagree) to 7 (totally agree).

Perceived Replacement. Because of lack of an existing measure, we designed three items $(\alpha=.78)$ based on statements made by the Danish politicians, right-wing intellectuals, and the media (e.g., "Because of a rapidly growing population of Muslims in Denmark, I feel alienated in my own country") to measure perceived replacement.

Symbolic Threat. Three items $(\alpha=.95)$ from Obaidi et al., (2018a; e.g., "Danish norms and values are being threatened by Muslims) were used to measure symbolic threat.

Realistic Threat. An additional three items $(\alpha=.85)$ from Obaidi et al. (2018a; e.g., "Because of the presence of Muslims, Danish people have fewer resource)were also used to measure realistic threat.

\footnotetext{
${ }^{1}$ For this and the remaining studies, when percentages for the demographic variable do not add up to $100 \%$, this is due to missing values.
} 
THE GREAT REPLACEMENT CONSPIRACY AND ANTI-MUSLIM RESENTMENT

Violent Behavioural Intentions. Violent behavioural intentions were measured using seven items (e.g., "I will personally use violence against people harming other Danes that I care about"; $\alpha=.80$ ) adopted from Obaidi et al., (2018a \& 2018b).

Islamophobia. The 8-item behavioral-affective subscale of the Islamophobia scale (Lee et al., 2009) was used to measure participants' hostility toward Muslims ( $\alpha=$ .94). Specifically, on 10-point Likert scales ranging from 1 (totally disagree) to 10 (totally agree), participants were asked to indicate their agreement with statements such as, "Just to be safe, it is important to stay away from places where Muslims could be."

Muslim persecution. Muslim persecution was measured with 6-items adapted from Altemeyer's (1996) POSSE measure (see also Obaidi et al., 2018b). Participants were asked to "imagine that someday in the future the Danish government decides to outlaw Muslim organizations and requests all citizens to do their best to make sure that the law has a successful effect" and then to indicate how much they agreed with items about Muslim persecution (e.g., "I would support the execution of Muslim leaders", $\alpha=$ 92).

\section{Results}

Variable descriptives and correlations for Studies 1 (as well as Studies 2 \& 3) can be found in Table 1 .

Perceived replacement of the autochthonous population was positively correlated with willingness to violently persecute Muslims, violent intentions, Islamophobia, symbolic, and realistic threat perceptions (see Table 1). Moreover, both types of threats were related to the Muslim persecution and Islamophobia. However, only symbolic threat was associated with violent intentions. 
THE GREAT REPLACEMENT CONSPIRACY AND ANTI-MUSLIM RESENTMENT

Table 1

Descriptive statistics and variable intercorrelations for Studies 1, 2 and 3.

\begin{tabular}{|c|c|c|c|c|c|c|c|c|}
\hline & Variables & $M$ & $S D$ & 2. & 3. & 4. & 5 & 6 \\
\hline 毞交 & $\begin{array}{l}\text { 1. Perceived Replacement } \\
\text { 2. Perceived Realistic Threat } \\
\text { 3. Perceived Symbolic Threat } \\
\text { 4. Violent Behavioral Intentions } \\
\text { 5. Islamophobia } \\
\text { 6. Muslim Persecution }\end{array}$ & $\begin{array}{l}1.69 \\
2.37 \\
2.14 \\
2.26 \\
1.40 \\
1.36\end{array}$ & $\begin{array}{l}1.20 \\
1.43 \\
1.65 \\
1.21 \\
0.96 \\
0.89\end{array}$ & $.59 * *$ & $\begin{array}{l}.72 * * \\
.67 * * \\
-\end{array}$ & $\begin{array}{l}.32 * * \\
.14 \\
.30^{* *} \\
-\end{array}$ & $\begin{array}{l}.81 * * \\
.58 * * \\
.71 * * \\
.22 * \\
-\end{array}$ & $\begin{array}{l}.59^{* *} \\
.51^{* *} \\
.58^{* *} \\
.29^{* *} \\
.77^{* *} \\
-\end{array}$ \\
\hline 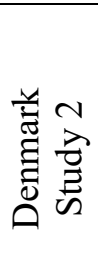 & $\begin{array}{l}\text { 1. Perceived Replacement } \\
\text { 2. Perceived Realistic Threat } \\
\text { 3. Perceived Symbolic Threat } \\
\text { 4. Violent Behavioral Intentions } \\
\text { 5. Islamophobia } \\
\text { 6. Muslim Persecution }\end{array}$ & $\begin{array}{l}2.02 \\
1.96 \\
2.58 \\
2.03 \\
1.58 \\
1.81\end{array}$ & $\begin{array}{l}1.33 \\
1.14 \\
1.71 \\
1.65 \\
1.12 \\
1.45\end{array}$ & $\begin{array}{l}.49^{* *} \\
-\end{array}$ & $\begin{array}{l}.65 * * \\
.68 * * \\
-\end{array}$ & $\begin{array}{l}.68^{* *} \\
.41^{* *} \\
.66^{* *} \\
-\end{array}$ & $\begin{array}{l}.61 * * \\
.48 * * \\
.67 * * \\
.65 * * \\
-\end{array}$ & $\begin{array}{l}.72^{* *} \\
.51^{* *} \\
.75^{* *} \\
.75^{* *} \\
.65^{* *} \\
-\end{array}$ \\
\hline 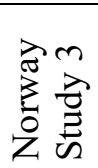 & $\begin{array}{l}\text { 1. Perceived Realistic Threat } \\
\text { 2. Perceived Symbolic Threat } \\
\text { 3. Islamophobia }\end{array}$ & $\begin{array}{l}2.88 \\
2.54 \\
3.47\end{array}$ & $\begin{array}{l}1.49 \\
1.35 \\
3.01\end{array}$ & - & $\begin{array}{l}.78 * * \\
-\end{array}$ & $\begin{array}{l}.79 * * \\
.69 * * \\
-\end{array}$ & & \\
\hline
\end{tabular}

Next, we examined a path model, in which symbolic and realistic threats mediated the link between perceived replacement of the autochthonous population and Muslim persecution, violent intentions, and Islamophobia. In this and all remaining studies, the model was estimated using Robust Maximum Likelihood (MLR) in MPlus (version 7; Muthén \& Muthén, 2012) in order to account for skewed variables. Full information maximum likelihood (FIML) was used to handle missing data $(<3 \%)$. In this (fully saturated) mediation model, perceived replacement predicted both symbolic and realistic threats and, of these, symbolic threat predicted all three dependent variables while we did not find a significant relation between realistic threat and any of the dependent variables. Further, perceived replacement predicted all the key variables except violent behavioral intentions (see Figure 1), suggesting full and partial mediation. 
THE GREAT REPLACEMENT CONSPIRACY AND ANTI-MUSLIM RESENTMENT

Based on bootstrapping with 5,000 random re-samples, perceived replacement had an indirect and positive effect on violent intentions $(\beta=.27,95 \% \mathrm{CI}[.05, .68])$, Islamophobia $(\beta=.17,95 \%$ CI $[.05, .43])$, and Muslim persecution $(\beta=.22,95 \%$ CI $[.04$, $.57]$ ) as mediated by symbolic threat. Indirect effects associating perceived replacement and our dependent variables through realistic threat did not yield significance (violent intentions, $\beta=-.07,95 \% \mathrm{CI}[-.35, .11]$, Islamophobia, $\beta=.04,95 \% \mathrm{CI}[-.10, .22]$, and Muslim persecution $(\beta=.06,95 \%$ CI $[-.10, .31])$.

Next, we constrained the paths from symbolic and realistic threats separately to each dependent variable to test whether the differences between these paths were statistically significant. When the paths from symbolic and realistic threats to violent intentions were constrained to equality, this produced a significant deterioration in model fit (Chi-Square Difference, $\left.\Delta \chi^{2}(1)=4.36, p=.031\right)$, suggesting a statistically significant difference between both paths. However, we did not find any significant difference between realistic and symbolic threats to Muslim persecution (Chi-Square Difference, $\left.\Delta \chi^{2}(1)=0.72, p=.396\right)$ and Islamophobia (Chi-Square Difference, $\Delta \chi^{2}(5)=0.99, p=$ .319 . 


\section{Figure 1}

Path Model for Study 1

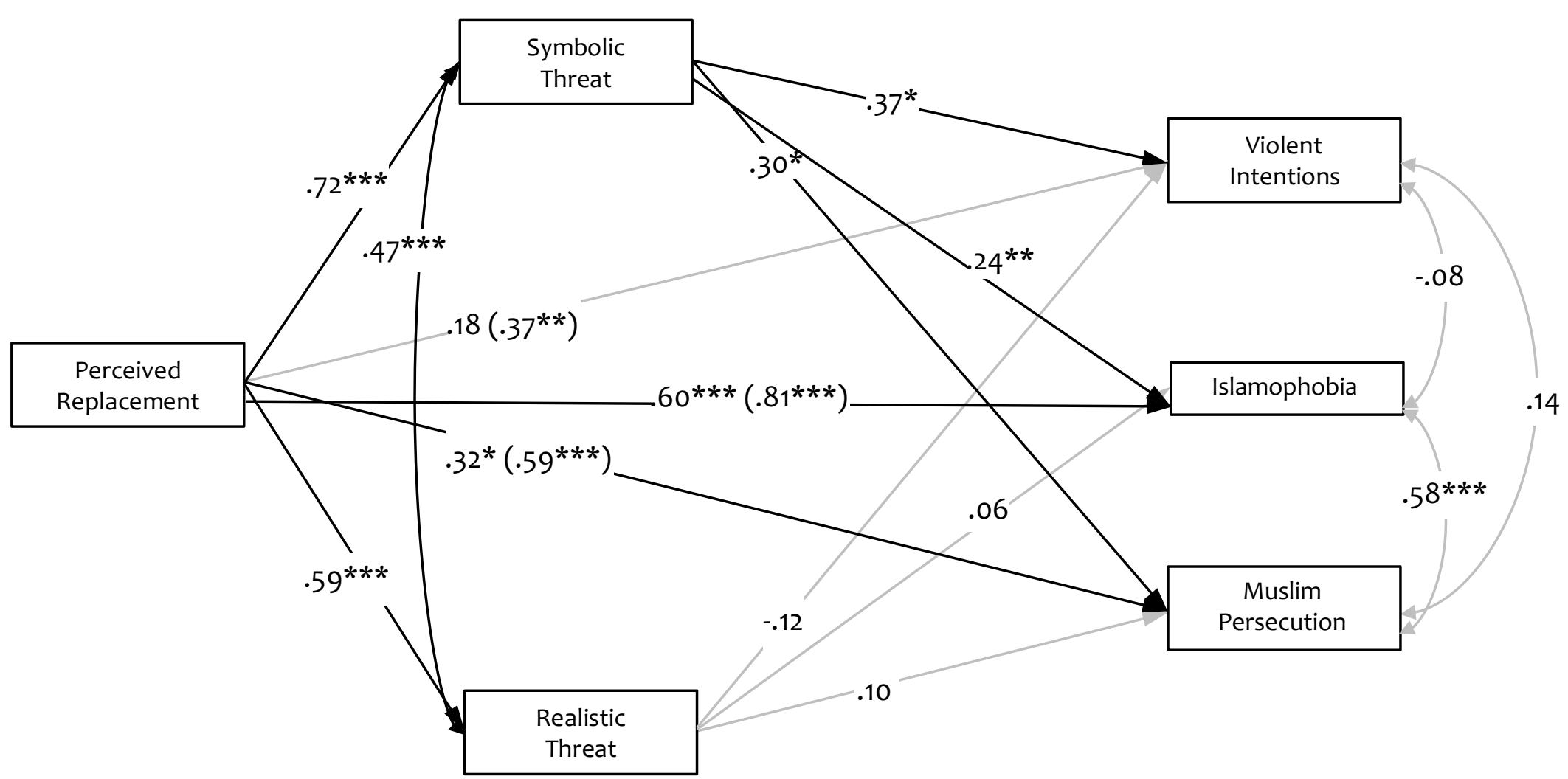

Note. Standardized coefficients are displayed. ${ }^{*} p<.05,{ }^{*} p<.01, * * * p<.001$. The non-significant paths are displayed in grey. For each dependent variable the direct effect from the unmediated model is presented in parentheses. 
We also tested whether these relations were robust to the introduction of demographic variables for age, gender, education, and socioeconomic status. With the exception of the paths from symbolic threat to violent intention $(\beta=.24, p=.080)$, and perceived replacement to Muslim persecution $(\beta=.22, p=.075)$, which turned marginally significant, the remaining paths remained just as strong in this analysis $(\beta s \geq 0.26, p s \leq$ $.024)$.

\section{Preliminary discussion}

Study 1 showed that perceived replacement was associated with both general (e.g., Islamophobia) and extreme negative anti-Muslim resentment (e.g., Muslim persecution). Moreover, this relationship was mediated by symbolic threat perceptions. However, a central limitation of this study is that our independent variable could be perceived as a proxy variable. More specifically, rather than using a direct measure of perceived replacement, we measured the feeling of becoming alienated due to increased Muslim migration. Study 2 remedies this limitation by directly assessing the perception that one's group is being replaced or becoming extinct.

\section{Study 2}

We had several aims with Study 2. First, to test the robustness of our results, we wanted to replicate our results from Study 1 with another sample of White Danes.

Second, we aimed to address the measurement limitation of the previous study by employing a more extensive and direct measure of perceived replacement of one's group by an outgroup using the words "replaced" and "extinct".

\section{Method}


THE GREAT REPLACEMENT CONSPIRACY AND ANTI-MUSLIM RESENTMENT

\section{Participants and Procedure}

As in Study 1, we aimed to recruit at least 150 White Danish participants to have enough power to test the proposed mediation model. A total of 218 White Danish participants $\left(M_{\mathrm{age}}=28.49, S D_{\mathrm{age}}=8.64\right.$; Age range: $18-55 ; 51.1 \%$ females $)$ were recruited in the same manner as Study 1 yet only Facebook was used. Of the total sample, $44.6 \%$ were enrolled in university studies, $20.3 \%$ had completed high school, $17.8 \%$ had a bachelor's degree, 9.9\% had a post-graduate degree, and $7.4 \%$ had completed upper secondarily school. Moreover, $52 \%$ identified as being middle class, $20.5 \%$ as being upper middle class, $17.5 \%$ as being working class and $10 \%$ being upper class.

\section{Measures}

Different from the previous study, we used four items to measure the perceived replacement of White Danes by Muslims (e.g., “The population replacement in Denmark will make Muslims a majority in the near future”; $\alpha=.81$ ). Moreover, these new items were created based on statements expressed by the proponents of the "Great Replacement" conspiracy such as GI and specifically included the words "replaced" or "extinct". Next, using the same measures as in Study 1, we assessed symbolic threat $(\alpha=.94)$, realistic threat $(\alpha=.86)$, violent behavioral intentions $(\alpha=.95)$, Islamophobia $(\alpha=.93)$, and Muslim persecution $(\alpha=.95)$.

\section{Results}

Variable descriptives and correlations can be found in Table 1 above. Perceived replacement was positively correlated with violent behavioral intentions, Muslim persecution, Islamophobia, and the two threat perceptions (see Table 1). Moreover, symbolic threat, but not realistic threat, was positively associated with the three 
THE GREAT REPLACEMENT CONSPIRACY AND ANTI-MUSLIM RESENTMENT

dependent variables.

As in Study 1, symbolic but not realistic threat mediated all associations between perceived replacement of the autochthonous population and the dependent variables (see Figure 2). Based on bootstrapping with 5,000 random re-samples, perceived replacement had significant indirect and positive effects on violent intentions $(\beta=.31,95 \% \mathrm{CI}[.28$, $.62])$, Islamophobia $(\beta=.36,95 \% \mathrm{CI}[.34, .71])$, and Muslim persecution $(\beta=.43,95 \%$

CI $[.46, .78])$, that were mediated by symbolic threat. No mediation by realistic threat was observed (indirect effects on violent intentions, $\beta=-.05,95 \%$ CI [-.21, .04], Muslim persecution, $\beta=.01,95 \% \mathrm{CI}[-.12, .11]$, and Islamophobia, $\beta=.03,95 \% \mathrm{CI}[-.07, .19])$.

Next, as in Study 1, we constrained the paths from symbolic and realistic threats to each dependent variable to equality to test whether the difference between these paths was statistically significant. When the paths from symbolic and realistic threats to violent intentions (Chi-Square Difference, $\left.\Delta \chi^{2}(1)=13.31, p=.001\right)$, Islamophobia (Chi-Square Difference, $\left.\Delta \chi^{2}(1)=7.31, p=.001\right)$, and Muslim persecution (Chi-Square Difference, $\left.\Delta \chi^{2}(1)=14.82, p=.001\right)$ were constrained, this produced a significant deterioration in model fit, suggesting a difference between the paths.

As in Study 1, we also tested whether the relations were robust to the introduction of demographic variables for age, gender, education, and socioeconomic status. All paths that were significant without these control variables remained as strong in this analysis $(\beta s \geq 0.20, p s \leq .019)$. 


\section{Figure 2}

Path Model for Study 2

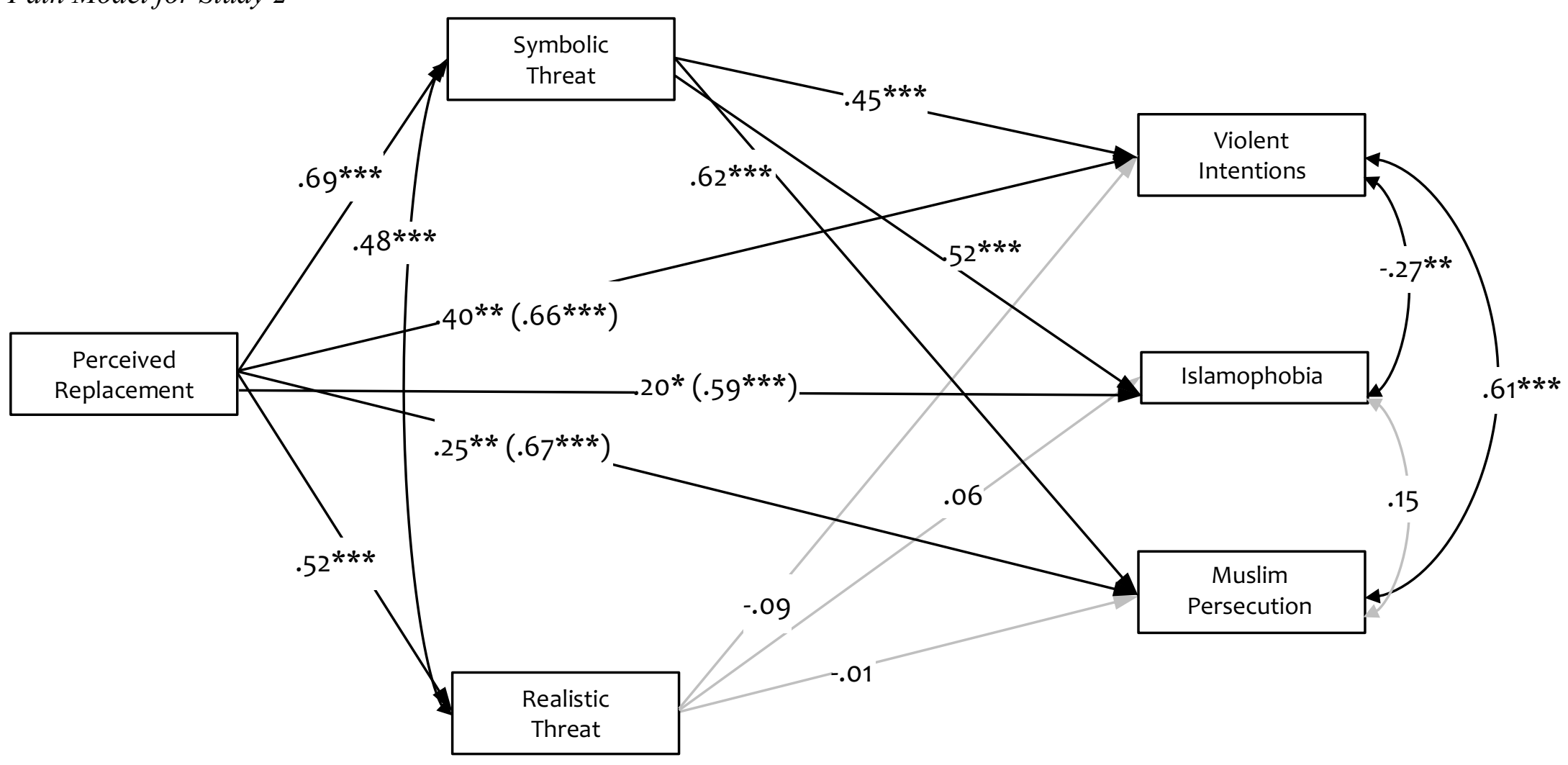

Note. Standardized coefficients are displayed. $* p<.05, * * p<.01, * * * p<.001$. The non-significant paths are displayed in grey. For each dependent variable the direct effect from the unmediated model is presented in parentheses. 
THE GREAT REPLACEMENT CONSPIRACY AND ANTI-MUSLIM RESENTMENT

\section{Preliminary discussion}

As in Study 1, this second study demonstrated that perceived replacement was associated with anti-Muslim resentment (e.g., Muslim persecution, violent intentions, and Islamophobia). Again, this relationship was mediated by symbolic threat perceptions. Although Studies 1 and 2 have supported the predicted relationships between perceived replacement and outgroup hostility a central limitation of the first two studies is the crosssectional data structure. Thus, the final study uses an experimental design to address this and, thus, assess causality.

\section{Study 3}

Although providing consistent results, the first two studies were limited as they employed correlational designs. Therefore, we aimed to conduct an experimental study, this time in Norway. Importantly, to replicate our findings, we randomly assigned participants to either a replacement or a control condition. Next, we assessed participants' symbolic and realistic threat perceptions and, to keep the survey brief, their degree of Islamophobia specifically. We hypothesized that participants who were assigned to the replacement condition would perceive more symbolic threat and subsequently show more Islamophobia than those in the control condition.

\section{Method}

\section{Participants}

A total of 96 White autochthonous Norwegians $\left(M_{\text {age }}=28.6\right.$ years, $S D_{\text {age }}=6.5$; Age range: $18-70 ; 79.2 \%$ male) were recruited through postings on online social networks (e.g., Facebook groups unrelated to the topic) for a study on "social issues." A power analysis indicated that this sample size provided $80 \%$ power to detect a medium- 
THE GREAT REPLACEMENT CONSPIRACY AND ANTI-MUSLIM RESENTMENT

sized effect $(d=.5)$ at a .05 significance criterion. About half of the participants $(44.8 \%)$

indicated that secondary school was their highest education, followed by a bachelor's degree $(39.6 \%)$, and a master's degree $(15.6 \%)$.

\section{Procedure}

Data was collected online and participants were randomly assigned to one of two conditions via Qualtrics software. In the replacement condition, participants watched a short, edited video clip from a major Norwegian TV channel. In the video, new, statistical reports were cited suggesting that ethnic Norwegians may become a minority in Norway within 50 years (and within 20 years in the capital city of Oslo specifically) due to immigration. While citing these reports, images were shown of Norwegian kindergartens comprising mostly children from Muslim-majority countries. In the control condition, participants watched an unrelated video from the same TV station that was matched in length and dealt with the importance of using eyeglasses while driving.

\section{Measures and Materials}

After watching the video, participants first completed the symbolic and realistic threat measures below in randomized order and then completed a measure of Islamophobia. $^{2}$

Symbolic Threat. The symbolic and realistic threat measure was based on statements made by the Norwegian politicians, right-wing intellectuals, and the media Participants were asked to indicate the degree to which they felt that different aspects of the Norwegian culture were threatened by immigration $(\alpha=.97)$. These aspects were Norwegian (1) cultural habits, (2) values and norms, (3) cultural traditions, and (4)

\footnotetext{
${ }^{2}$ The survey also included other measures intended for a different study on acculturation.
} 
THE GREAT REPLACEMENT CONSPIRACY AND ANTI-MUSLIM RESENTMENT

culture in general. Responses were rated on 5-point Likert scales ranging from 1 (not at all threatened) to 5 (threatened to a high degree).

Realistic Threat. Four items assessed realistic threat $(\alpha=.94)$ using the same prompt as for the symbolic threat measure described above. However, here, participants rated the degree to which they felt that the Norwegian (1) labor market, (2) welfare system, (3) economic wealth of Norwegian citizens, and (4) the Norwegian economy in general were threatened by immigration.

Islamophobia. To measure Islamophobia, we used the same items as in Studies 1 and $2(\alpha=.94)$, scored on a 0 (totally disagree) to 10 (totally agree) scale.

Manipulation check. Participants were asked to indicate to which extent they felt that the continued existence of the Norwegian ethnic group was threatened on four items $(\alpha=.99)$ such as, "To which extent do to you think the very existence of the Norwegian ethnic group is threatened by immigration?" The response format was the same as for the threat measures.

\section{Results}

The manipulation check supported the effectiveness of our manipulation. Participants in the replacement condition scored higher on the manipulation check $(M=$ $3.17, S D=1.45)$ than participants in the control condition $(M=2.44, S D=1.55, t(94)=-$ 2.37, $p=.020, d=.48)$.

Next, the experimental manipulation affected both symbolic and realistic threats, as well as Islamophobia: participants assigned to the replacement condition perceived higher degrees of symbolic $(M=3.21, S D=1.49)$ and realistic threats $(M=2.88, S D=$ 1.40) than those assigned to the control condition (symbolic threat: $M=2.56, S D=1.43$, 
$t(94)=-2.20, p=.030, d=.45$; realistic threat: $M=2.22, S D=1.22, t(94)=-2.46, p=$ $.016, d=.50$; also see Figure 3). Moreover, participants in the replacement condition expressed more Islamophobia $(M=4.11, S D=3.03)$ than those in the control group $(M=$ 2.84, $S D=2.89, t(94)=-2.09, p=.039, d=.43)$.

Figure 3

Mean Differences Observed in Study 3

๑ Control ๑ Replacement Condition
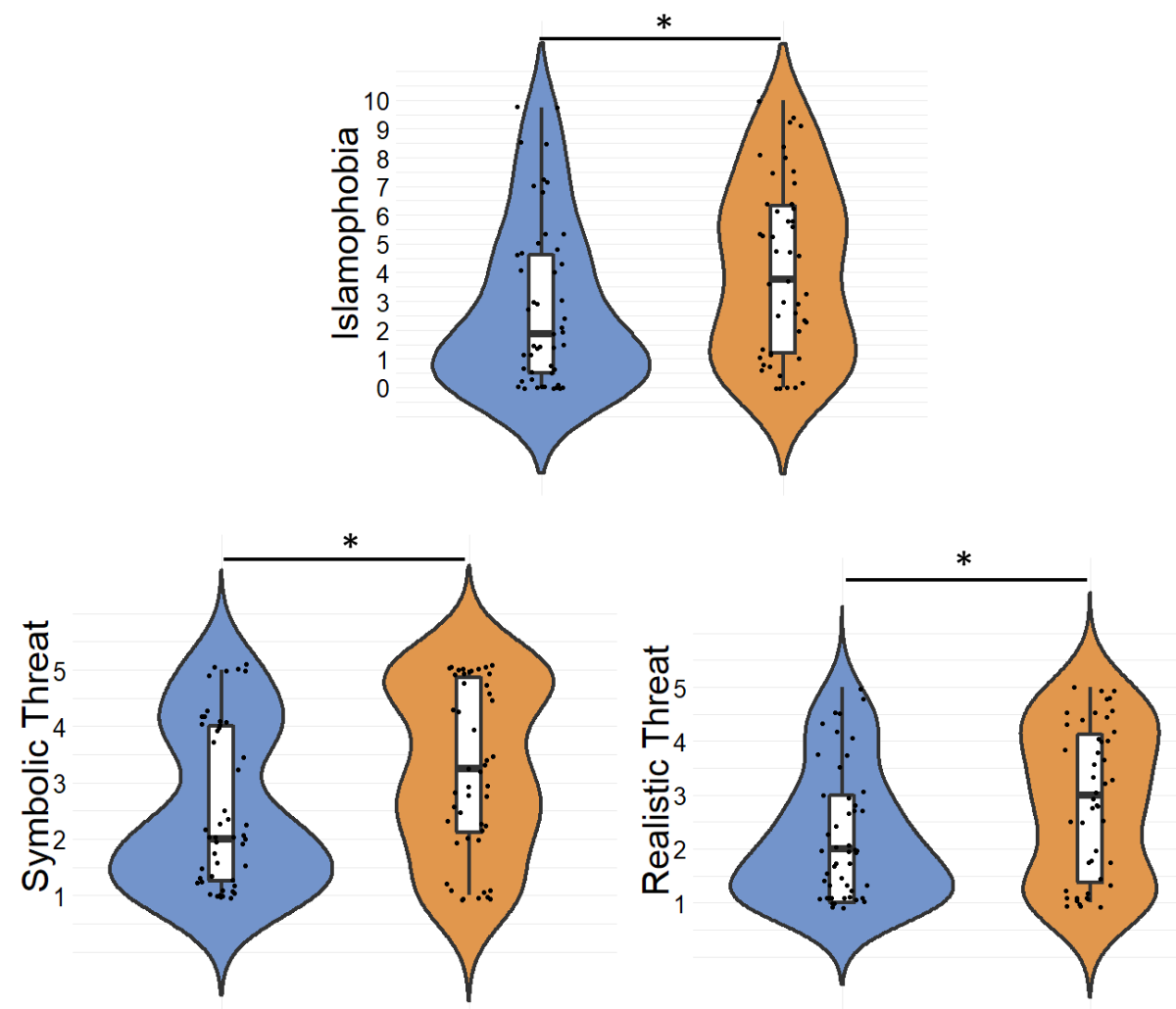

Note. ${ }^{*} p<.05$ 
THE GREAT REPLACEMENT CONSPIRACY AND ANTI-MUSLIM RESENTMENT

Having established these effects, we estimated a path model to test whether symbolic and realistic threats mediated the effects of the numerical threat condition $(0=$ control, 1 = replacement condition) on Islamophobia. In this (fully saturated) model, experimental threat predicted both symbolic and realistic threat; of these, only symbolic threat predicted Islamophobia as expected (see Figure 4).

When the paths from symbolic and realistic threats to Islamophobia were constrained to equality, this produced a significant deterioration in model fit, suggesting a difference between both paths (Chi-Square Difference, $\left.\Delta \chi^{2}(1)=4.80, p=.029\right)$. Analogously, analyses using bootstrapping with 5,000 random re-samples indicated that, whereas there was a significant indirect effect of the experimental condition on Islamophobia through symbolic threat $(\beta=.14,95 \% \mathrm{CI}[.02, .30])$, the indirect effect of the condition on Islamophobia through realistic threat was non-significant $(\beta=.05,95 \%$ CI $[-.01, .16])$.

Finally, we also tested whether these relations were robust to the introduction of demographic variables for age, gender and education. With the exception of the path from symbolic threat to Islamophobia, which became stronger $(\beta=.70, p=.001)$, the remaining paths remained just as strong in this analysis $(\beta s \geq 0.24, p s \leq .016)$.

\section{Preliminary discussion}

Study 3 supported the previous studies by providing causal support for the hypothesis that the perception of replacement may fuel Islamophobia among the White majority population and that this effect is mediated by higher perceptions of symbolic threat, but not realistic threat. 


\section{Figure 4}

Path Model for Study 4

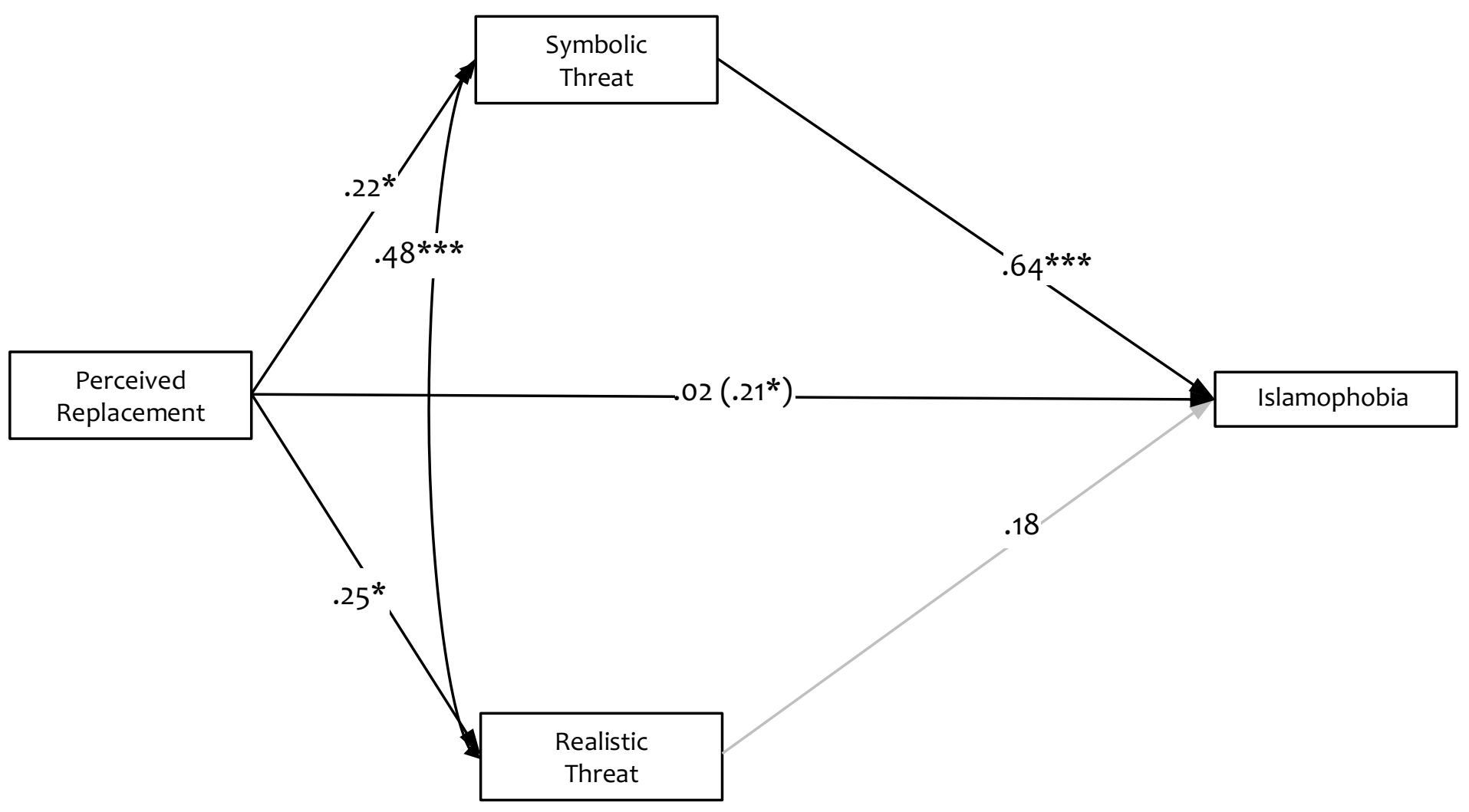

Note. Coefficients are standardized. ${ }^{*} p<.05,{ }^{*} p<.01,{ }^{* *} p<.001$. The non-significant paths are displayed in grey. The direct effect from the unmediated model is presented in parentheses. 
THE GREAT REPLACEMENT CONSPIRACY AND ANTI-MUSLIM RESENTMENT

\section{Discussion}

It has been suggested that immigration-related conspiracy theories trafficked by right-wing groups may nurture hate and violence against immigrants and asylum seekers in the West. Moreover, recent FBI documents predict that right-wing conspiracy-driven extremism will increase in the next few years (Steinbuch, 2019). Indeed, new reports indicate that far-right terrorism has significantly outpaced other forms of terrorism (Jones et al., 2020). More specifically, right-wing terrorist incidents in the West have increased by $320 \%$ over the past five years (Institute for Economics \& Peace, 2019). One of the most potent conspiracy theories evoked by right-wing extremists, politicians and commentators, is the "Great Replacement"- the conspiracy arguing that there is an attempt to replace the White autochthonous population with non-Western immigrants. Yet, to our knowledge, the present paper is the first to investigate the impact of perceiving that one's ethnic group may be replaced by non-Western immigrants on negative outgroup sentiment (e.g., Muslim persecution, violent intentions, and Islamophobia). Importantly, the perception of being replaced is distinct from perceptions of outgroup size in that it refers to extinction of one's group, whereas outgroup size is mainly related to a zero-sum game that the majority is losing. Here, in three studies (i.e., two correlational and one experimental), we tested the impact of this conspiracy while also examining the underlying role of symbolic and realistic threat perceptions.

Supporting our predictions, in the first two correlational studies, the perceived replacement of one's group was strongly associated with more intergroup hostility. In both studies, these effects were mediated by higher perceptions of symbolic threat, but not realistic threat. In the third study, we obtained experimental support for the assumed 
THE GREAT REPLACEMENT CONSPIRACY AND ANTI-MUSLIM RESENTMENT

causality between the constructs, as we manipulated the independent variable and tested effects on mediators and dependent variables. That is, experimentally altering the perceived replacement of one's population led to higher levels of Islamophobia compared to a plain control condition.

The effects of a perceived replacement were only mediated by symbolic threat. This is in line with recent studies (e.g., Obaidi et al., 2018a) investigating the relationship between identification, threat perception, and outgroup hostility in which symbolic threat emerged as the main predictor of the hostility. One explanation for this could be rooted in the kind of rhetoric used by the right-wing intellectuals, media, and politicians cultivating a clash of civilization discourse that portrays Muslims and depicts Islam as an imminent threat to the core values of Christian Western civilization (e.g., Fallaci, 2002; Huntington, 1993; Murray, 2017). Thus, the proponents of the "Great Replacement" conspiracy first and foremost see non-Western immigrants, particularly Muslims, as a threat to White European culture and Judeo-Christian civilization rather than a threat to Europeans' economic conditions. For example, the leading proponents of replacement conspiracy who are part of GI, lobby for an ethnically and religiously homogeneous Europe. To achieve this, they campaign for an indiscriminate expulsion of all non-Westerners who do not have a Judeo-Christian ethnic heritage. This ethno-nationalist view, and the need to protect the "White race, were recurring and dominant elements many recent White supremacists justification for carrying out their racially motivated violent attacks. For example, the El Paso shooter openly embraced the ethno-nationalist view and saw the alleged replacement of the White population as an attempt to remove White culture. Therefore, such narratives depicting Muslims as an existential threat to Western way of 
THE GREAT REPLACEMENT CONSPIRACY AND ANTI-MUSLIM RESENTMENT

life, national identity, and culture (i.e., Wilders, 2017) may result in an increased perception of cultural threat, incompatibility, and clash of values, leading to more symbolic threat perceptions among the majority population.

As for our dependent variables, we not only focused on general negative attitudes towards outgroups (e.g., Islamophobia), but also measured more extreme types of outgroup hostility such as violent behavioral intentions and willingness to violently persecute Muslim minority members. Based on previous studies (e.g., Tausch et al., 2011), one may have expected that the predictive power of perceived replacement would become weaker the more extreme the dependent variables become. However, our data did not support this proposition, and the results replicated across two studies, providing confirmation of the robustness of our model and illustrating the negative implication and the potential that the "Great Replacement" conspiracy has for radicalizing some people.

\section{Limitations and Future Directions}

One of the main limitations of the present research was the use of nonrepresentative samples, reducing our findings' generalizability and inference that can be made about the entire population. However, we believe that the fact that we observed the same pattern of results across three studies and two different cultural contexts (e.g., Norway and Denmark) attenuates such a concern to some extent. Nevertheless, future studies are needed to replicate our findings outside the Scandinavian context and among representative samples.

Another concern deals with the mediation models tested in our studies. In Studies 1 and 2, model estimation was based solely on correlational data and directionality was assumed based on previous work. Such models have only limited evidentiary value as 
THE GREAT REPLACEMENT CONSPIRACY AND ANTI-MUSLIM RESENTMENT

they preclude inferences of causality (Bullock et al., 2010; MacKinnon et al., 2007). To alleviate this limitation, in Study 3, we replicated the model by manipulating the independent variable. Nevertheless, it is important to note that the relationship between the mediators (i.e., symbolic and realistic threats) and the dependent variable still was correlational. Hence, future studies should attempt to manipulate both the independent and mediating variables to establish the full causal chain.

It is also important to note that we did not directly assess actual violence, which is practically and ethically very difficult in social science research. Instead, we measured violent intentions and hostile intergroup attitudes. Although we found consistent relationships between our independent and mediator variables and these outcomes, to what extent the measured intentions and attitudes translate into actual violent behavior remains uncertain.

Although, the effects of perceived replacement in this study were only mediated by symbolic threat, other studies show that Whites' experience of both aversive economic conditions (i.e., realistic threat) and increased exposure to non-White minorities are both associated with feelings of intergroup threat (e.g., Knowles \& Tropp, 2018). Particularly, previous studies have shown that increased ethno-racial diversity leads to a high degree of realistic threat under conditions in which economic resources are scarce (Quillian, 1995). Thus, the extent to which either a symbolic or realistic threat leads to outgroup hostility is influenced by the socioeconomic factors of a given context (McDemott et al., 2019; Nijs et al., 2021).

Furthermore, what kind of threat is the most potent predictor of outgroup hostility and prejudice depends on the group in question as different outgroups are perceived to 
pose different types of threats (e.g., Cottrell \& Neuberg, 2005). For instance, African Americans are generally perceived to pose realistic threats to Whites (e.g., Cottrell \& Nueberg, 2005). In contrast, Atheists and religious minorities (e.g., Muslims) are commonly perceived to pose symbolic threats (Gervais et al., 2011; Raiya et al., 2008). Identifying which specific groups and circumstances lead to distinct types of threats has implications for conflict and prejudice reduction as the interventions employed to reduce intergroup conflict should be developed to target the specific type of threat perception.

Finally, future studies should focus on individual-level variables as moderators of the relationship between perceived threat and radicalization. For example, individuals who have a predisposition to react negatively to uncertainty (Choi and Hogg, 2020) may perceive a higher degree of threat when confronted with information indicating that their group or culture is being replaced. Indeed, uncertainty experienced as a threat has been linked with protective behaviors (i.e., retreat into identity-focused echo chambers often evolving around populist ideology and conspiracy theories; Hogg, in press).

\section{Societal Implications}

As the writer Rosa Schwartzburg puts it 'the 'Great Replacement' is spreading like a virus" and seeping into mainstream conservative right-wing political discourse (Schwartzburg, 2019). For instance, the idea of being "replaced" by immigrants is a recurring feature on some Fox New programs on Fox News (e.g., hosts such as Tucker Carlson and Laura Ingraham). Indeed, a New York Times review of popular right-wing media platforms found a striking degree of overlap between the language used by the El Paso shooter and the incendiary language of right-wing media personalities that echo the fear of invasion and replacement (Peters et al., 2019). As our results show, such 
THE GREAT REPLACEMENT CONSPIRACY AND ANTI-MUSLIM RESENTMENT

incendiary language portraying Westerners under invasion by immigrants has farreaching implications for violent extremism. For instance, recent analyses identified fear of "the Great Replacement" as the root cause of the Capitol attack; these analyses concluded that the second biggest driver for the attack is the significant traction that such conspiracy theories have on social media (Pape, 2021).

In addition to its potential to lead to violent extremism, such incendiary rhetoric adopting themes of the "Great Replacement" conspiracy may legitimatize violence. Specifically, because it portrays the majority population as victims whose ethnicity is under existential threat, it may help justifying violence as a necessary mean to avert such threats (Bandura, 1999; Kruglanski et al., 2014). This is clearly visible in El Paso shooters' manifesto claiming that he was "simply defending my country from cultural and ethnic replacement brought on by an invasion." (Baker \& Shear, 2019).

Finally, such apocalyptic discourse of "White genocide" and invasion of Europe by non-Western immigrants has far-reaching policy implications. When faulty or distorted beliefs about immigrants replacing the majority population are taken as fact, they become the basis for generating hostile public opinion towards immigrants. This may result in threat perception and fear of immigrants, which in turn can result in discriminatory public policies and actions leading to greater polarization and intergroup conflict. 
THE GREAT REPLACEMENT CONSPIRACY AND ANTI-MUSLIM RESENTMENT

\section{Reference list}

Adida, L. C., Laitin, D. D., \& Valfort, M. (2016). Why Muslim integration fails in Christian heritage societies: Harvard University Press.

Alba, R. (2018). What majority-minority society? A critical analysis of the Census Bureau's Projections of America's demographic future. Sociological Research for a Dynamic World. 4, 1-10.

Alba, R., Rumbaut, R. G., Marotz, K. (2005). A distorted nation: Perceptions of racial/ethnic group sizes and attitudes toward immigrants and other minorities. Social Forces, 84, 901-919.

Alduy, C. (2017, April 23). What a 1973 French novel tells us about Marine Le Pen, Steve Bannon and the rise of the populist right. Politico Magazine, https://www.politico.com/magazine/story/2017/04/23/what-a-1973-french-noveltells-us-about-marine-le-pen-steve-bannon-and-the-rise-of-the-populist-right215064

Allport, G. W. (1954). The nature of prejudice: Perseus Books.

Altemeyer, B. (1996). The authoritarian specter: Harvard University Press.

Arango, T., Bogel-Burroughs, N., \& Benner, K. (2019, August 3). Minutes Before El Paso Killing, Hate-Filled Manifesto Appears Online. The New York Times. https://www.nytimes.com/2019/08/03/us/patrick-crusius-el-paso-shootermanifesto.html?smid=fb-nytimes\&smtyp $=$ cur\&fbclid $=$ IwAR1eM1bfV8SK3uFFLgjqnFVtFVEeNnIXa7M V_dRUJQOGaCXzU_t0a196N_Q 
THE GREAT REPLACEMENT CONSPIRACY AND ANTI-MUSLIM RESENTMENT

Bak, M., Tarp, K. N., \& Liang, C, S. (2019). Defining the concept of 'violent extremism` Geneva Paper 24/19. https://dam.gcsp.ch/files/2y10xuCSaBlvYTDbinjPokvyDO2XLpn5jG4va93JVUzpp qj08EDHwnC

Baker, P, \& Shear, D., M. (2019, August 4). El Paso shooting suspect's manifesto echoes Trump's language. The New York Times. https://www.nytimes.com/2019/08/04/us/politics/trump-mass-shootings.html

Bandura A. (1999). Moral disengagement in the perpetration of inhumanities. Personality Social Psychology Review, 3, 193-209.

Bansak, K., Hainmueller, J., \& Hanggartner, D. (2016). How economic, humanitarian, and religious concerns shape European attitudes toward asylum seekers. Science, 354(6309), 217-222.

Bélanger, J. J., Moyano, M., Muhammad, H., Richardson, L., Lafrenière, M. K., McCaffery, P., Framand, K., \& Nociti, N. (2019). Radicalization Leading to Violence: A Test of the 3N Model. Frontiers in psychiatry, 10, 42. doi.org/10.3389/fpsyt.2019.00042

Bellware, K. (2019, November 13). Leaked Stephen Miller emails show Trump's point man on immigration promoted white nationalism, SPLC reports The Washington Post. https://www.washingtonpost.com/politics/2019/11/12/leaked-stephen-milleremails-suggest-trumps-point-man-immigration-promoted-white-nationalism/

Bennhold, K. (2019, March 27). Donation from New Zealand attack suspect puts spotlight on Europe's far right. The New York Times. 
THE GREAT REPLACEMENT CONSPIRACY AND ANTI-MUSLIM RESENTMENT

https://www.nytimes.com/2019/03/27/world/europe/new-zealand-attack-europefar-right.html

Bilefsky, D. (2006, February 12). Cartoon dispute prompts identity crisis for liberal Denmark. The New York Times. https://www.nytimes.com/2006/02/12/international/europe/12denmark.html

Blalock, H. M. (1967). Toward a theory of minority-group relations: John Wiley.

Blinder, S. (2013). "Imagined Immigration: The Impact of Different Meanings of 'Immigrants' in Public Opinion and Policy Debates in Britain.” Political Studies, 63, 80-100. doi:10.1111/1467-9248.12053.

Bullock, J.G., Green, D.P., \& Ha, S.E. (2010). Yes, but what's the mechanism? (Don't expect an easy answer). Journal of Personality and Social Psychology, 98, 550558.

Card, D., Mas, A., \& Rothstein, J. (2008). “Tipping and the dynamics of segregation.” Quarterly Journal of Economics, 123(1): 177-218.

Chavez, N, Grinberg E., \& McLaughlin, C, E. (2018, October 31). Pittsburgh synagogue gunman said he wanted all Jews to die, criminal complaint says. CNN. https://edition.cnn.com/2018/10/28/us/pittsburgh-synagogueshooting/index.html

Choi, E. U., \& Hogg, M. A. (2020). Self-uncertainty and group identification: A metaanalysis. Group Processes \& Intergroup Relations, 23(4), 483501. doi.org/10.1177/1368430219846990 
THE GREAT REPLACEMENT CONSPIRACY AND ANTI-MUSLIM RESENTMENT

Cottrell, C. A., \& Neuberg, S. L. (2005). Different emotional reactions to different groups: a sociofunctional threat-based approach to "prejudice". Journal of Personality and Social Psychology. doi.org/10.1037/0022-3514.88.5.770

Cox. S., \& Meisel, A. (2018, September 20). Martin Sellner: The new face of the far right in Europe. BBC NEWS, https://www.bbc.com/news/stories-45572411

Craig, M. A., \& Richeson, J. A. (2014a). On the precipice of a "majority minority" America: Perceived status threat from the racial demographic shift affects white Americans' political ideology. Psychological Science 25 (6): 1189-97.

Craig, M. A., \& Richeson, J. A. (2014b). More diverse yet less tolerant? How the increasingly-diverse racial landscape affects White Americans' racial attitudes. Personality and Social Psychology Bulletin, 40(6), 750-761.

Craig, M. A., \& Richeson, J. A. (2017). Information about the U.S. racial demographic shift triggers concern about anti-white discrimination among the prospective white “minority." PLoS ONE 12 (9): e0185389.

Craig, M. A., Rucker, J. M., \& Richeson, J. A. (2018). Racial and political dynamics of an approaching "majority-minority" United States. The Annals of the American Academy of Political and Social Science, 667, 204-214.

Danbold, F., \& Huo, Y. J. (2015). No longer “all-American”? Whites' defensive reactions to their numerical decline. Social Psychological and Personality Science, 6, 210-218.

Danbold, F., \& Huo, Y. J. (2017). Men's defense of their prototypicality undermines the success of women in STEM initiatives. Journal of Experimental Social Psychology, 72, 57-66. 
THE GREAT REPLACEMENT CONSPIRACY AND ANTI-MUSLIM RESENTMENT

Davey, J., \& Ebner, J. (2019). “The “Great Replacement”: The violent consequences of mainstreamed extremism, Institute for Strategic Dialogue. https://www.isdglobal.org/wp-content/uploads/2019/07/The-Great-ReplacementThe-Violent-Consequences-of-Mainstreamed-Extremism-by-ISD.pdf

Dinas, E., Matakos, K., Xefteris, D., \& Hangartner, D. (2019). Waking up the golden dawn: does exposure to the refugee crisis increase support for extreme-right parties? Political Analysis, 27(2), 244-254. doi:10.1017/pan.2018.48

Fallaci, O. (2002). The Pride and the Rage. New York: Rizzoli International.

Feder, J, L., \& Maplestone, Z. (2019, March 29). The far-right group the Christchurch suspect donated to held an anti-immigrant protest in France. now it's facing new calls to be banned, BuzzFeedNews, https://www.bibme.org/citation-guide/apa/newspaper/

Fekete, L. (2012). 'The Muslim conspiracy theory and the Oslo massacre', Race \& Class, 53(3), 30-47, doi/ abs/10.1177/0306396811425984?journalCode=racb.

Gervais, W. M., Shariff, A. F., \& Norenzayan, A. (2011). Do you believe in atheists? Distrust is central to anti-atheist prejudice. Journal of Personality and Social Psychology, 101(6), 1189-1206. doi:10.1037/a0025882

Gorodzeisky A, Semyonov M. (2009). Terms of exclusion: public views towards admission and allocation of rights to immigrants in European countries. Ethnic and Racial Studies, 32, 401-23

Green, D. P., Strolovitch, D. Z., \& Wong, J. S. (1998). Defended neighborhoods, integration, and racially motivated crime. American Journal of Sociology, 104, $372-403$. 
THE GREAT REPLACEMENT CONSPIRACY AND ANTI-MUSLIM RESENTMENT

Hainmueller, J., \& Hopkins, D. J. (2014). Public attitudes toward immigration. Annual Review of Political Science, 17(1), 225-249. doi.org/10.1146/annurev-polisci$102512-194818$

Hangartner, D., E. Dinas, M. Marbach, K. Matakos, \& Xefteris, D. (2019). “Does exposure to the refugee crisis make natives more hostile?" American Political Science Review, 113, 442-455.

Hervik, P. (2012). The Danish Muhammad cartoon conflict. Current Themes in IMER Research, 13. Institute for Studies of Migration.

Hogg, M. A. (in press). Uncertain self in a changing world: A foundation for radicalisation, populism, and autocratic leadership. European Review of Social Psychology.

Huntington, S. (1993). The Clash of Civilizations. Foreign Affairs, 72, 22-49.

Institute for Economics \& Peace. Global Terrorism Index (2019, November, 20). Measuring the Impact of Terrorism, Sydney, http://visionofhumanity.org/reports Jardina, A. (2019). White identity politics: Cambridge University Press.

Jones, G., S., Doxsee, C., \& Harrington, N. (2020). The escalating terrorism problem in the United States. CSIS brief, Center for strategic and international studies.

Jupskås, A.R. (Red) \& Leidig, E. (Red). (2020). Knowing what's (far) right: A compendium. C-REX- Center for Research on Extremism, University of Oslo.

Kingsley, P. (2019, March 15). New Zealand massacre highlights global reach of White extremism. The New York Times. https:/www.nytimes.com/2019/03/15/world/asia/christchurch-mass-shootingextremism.html 
THE GREAT REPLACEMENT CONSPIRACY AND ANTI-MUSLIM RESENTMENT

Kjærsgaard, P. (2020, Febrary 3). Hverdagsjihad er et resultat af den stigende befolkningsudskiftning. Jyllands-Posten. https://jyllandsposten.dk/debat/breve/ECE11898153/hverdagsjihad-er-et-resultat-af-denstigende-befolkningsudskiftning/

Knowles, E. D., \& Tropp, L. R. (2018). The racial and economic context of Trump support: Evidence for threat, identity, and contact effects in the 2016 presidential election. Social Psychological and Personality Science, 9, 275-284. doi.org/10.1177/1948550618759326.

Krueger, A., B., \& Pischke, J. (1997). “A statistical analysis of crime against foreigners in United Germany." Journal of Human Resources, 32(1): 182-209.

Kruglanski A.,W, Gelfand M.,J, Bélanger J., J, Sheveland A, Hetiarachchi M, \& Gunaratna R. (2014). The psychology of radicalization and deradicalization: how significance quest impacts violent extremism. Political Psychology, 35, 69-93.

Lange, L. (2016, June 11). -Bytter ut befolkningen. Nettavisen Nyheter. https://www.nettavisen.no/nyheter/--bytter-ut-befolkningen/3171884.html

Lee, S. A., Gibbons, J. A., Thompson, J., M, \& Timani, H., S. (2009). The Islamophobia Scale: Instrument Development and Initial Validation, The International Journal for the Psychology of Religion, 19(2), 92-105, doi: 10.1080/10508610802711137

Lyons, C., J. (2008). Defending turf: Racial demographics and hate crime against Blacks and Whites. Social Forces, 87, 357-385

MacKinnon, D., P., Fairchild, A., J., \& Fritz, M., S. (2007). Mediation Analysis. Annual Review of Psychology, 58:1, 593-614. 
THE GREAT REPLACEMENT CONSPIRACY AND ANTI-MUSLIM RESENTMENT

McAlexander, (2019). How are immigration and terrorism related? An analysis of right- and left-wing terrorism in Western Europe, 1980-2004. Journal of Global Security Studies, 5, 179-195. doi.org/10.1093/jogss/ogy048

McDermott, M., Knowles, E. D., \& Richeson, J. A. (2019). Class Perceptions and Attitudes Toward Immigration and Race Among Working-Class Whites 1. Analyses of Social Issues and Public Policy, 19(1), 349 - 380 doi.org/10.1111/asap.12188

Miller, E, M. (2019, December 27). Hunting black men to start a 'race war'. The New York Times. https://www.washingtonpost.com/graphics/2019/local/race-warmurder-hate-crime/

Murray, D. (2017). The Strange Death of Europe: Immigration, Identity, Islam. London: Bloomsbury Continuum.

Muthén, J. K., \& Muthén, B. O. (2012). Mplus user's guide (7th ed.). Los Angeles, CA: Author.

Mutz, C., D. (2018). Status threat, not economic hardship, explains the 2016 presidential vote. Proceedings of the National Academy of Sciences, 115 (19) E4330E4339; doi:10.1073/pnas.1718155115

Myers, D., \& Levy, M. (2018). Racial population projections and reactions to alternative news accounts of growing diversity. The ANNALS of the American Academy of Political and Social Science, 677(1), 215228. doi.org/10.1177/0002716218766294 
THE GREAT REPLACEMENT CONSPIRACY AND ANTI-MUSLIM RESENTMENT

Nijs, T., Verkuyten, M., \& Martinovic, B. (2021). Losing what is OURS: The intergroup consequences of collective ownership threat. Group Processes \& Intergroup Relations. doi.org/10.1177/1368430220980809

Obaidi, M., Kunst, R. J., Kteily, N., Thomsen, L., \& Sidanius, J. (2018a). Living under threat: Mutual threat perception drives anti-Muslim and anti-Western hostility in the age of terrorism. European Journal of Social Psychology, 48, 567-584. doi:10.1002/ejsp.2362

Obaidi, M., Thomsen, L., \& Bergh, R. (2018b). “They think we are a threat to their culture": Meta-cultural threat fuels willingness and endorsement of extremist violence against the cultural outgroup. International Journal of Conflict and Violence, 12, 1-13. doi: 10.4119/UNIBI/ijcv.647.

Outten, H. R., Schmitt, M. T., Miller, D. A., \& Garcia, A. L. (2012). Feeling threatened about the future: Whites' emotional reactions to anticipated ethnic demographic changes. Personality and Social Psychology Bulletin, 38, 14-25.

Ozer, S., Obaidi, M., \& Pfattheicher, S. (2020). Group membership and radicalization: A cross-national investigation of collective self-esteem underlying extremism. Group Processes \& Intergroup Relations, 23(8), 12301248. doi.org/10.1177/1368430220922901

Pedersen, H, M. (2019, March 20). New Zealand-angreb fordømmes på den radikale højrefløj, men motivet kaldes 'en sund reaktion på objektive fakta' Information. https://www.information.dk/udland/2019/03/new-zealand-angrebfordoemmes-paa-radikale-hoejrefloej-motivet-kaldes-sund- reaktion-paaobjektive-fakta. 
THE GREAT REPLACEMENT CONSPIRACY AND ANTI-MUSLIM RESENTMENT

Peters, J., Grynbaum, M, M., Collins, K., Harris, R., \& Taylor, R. (2019, August 11). How the El Paso Killer Echoed the Incendiary Words of Conservative Media Stars. The New York Times. https://www.nytimes.com/interactive/2019/08/11/business/media/el-paso-killerconservative-media.html

Pew Research Center. (2013). “Immigration: Key Data Points from Pew Research.” Pew Research Center, December 23.

Piazza, J., A. (2017). "The determinants of domestic right-wing terrorism in the USA: economic grievance, societal change, and political resentment. Conflict Management and Peace Science 34(1), 52-80

Pape, R., A. (2021, April 6). What an analysis of 337 Americans arrested or charged in the Capitol insurrection tells us. The Washington Post, https://www.washingtonpost.com/opinions/2021/04/06/capitol-insurrectionarrests-cpost-analysis/

Quillian, L., (1995). Prejudice as a response to perceived group threat: Population composition and anti-immigrant and racial prejudice in Europe. American Sociological Review 60, 586-611.

Raiya, H. A., Pargament, K. I., Mahoney, A., \& Trevino, K. (2008). When Muslims are perceived as a religious threat: Examining the connection between desecration, religious coping, and anti-Muslim attitudes. Basic and Applied Social Psychology, 30(4), 311-325. doi.org/10.1080/01973530802502234 
THE GREAT REPLACEMENT CONSPIRACY AND ANTI-MUSLIM RESENTMENT

Reiermann, J., \& Andersen, K., T. (2019, October 21). Hver fjerde dansker: Muslimer skal ud af Danmark. Mandag morgen. https:/www.mm.dk/artikel/hver-fjerde-danskermuslimer-skal-ud-af-danmark

Savelkoul, M., Scheepers, P., Tolsma, J., \& Hagendoorn, L. (2010). Anti-Muslim attitudes in the netherlands: Tests of contradictory hypotheses derived from ethnic competition theory and intergroup contact theory. European Sociological Review, 27, 741-758.

Scheepers, P., Gijsberts, M., \& Coenders, M. (2002). Ethnic exclusionism in European countries public opposition to civil rights for legal migrants as a response to perceived ethnic threat. European Sociological Review, 1(18), 17-34.

Schlueter, E., \& Scheepers, P. (2010). The relationship between outgroup size and antioutgroup attitudes: A theoretical synthesis and empirical test of group threat- and intergroup contact theory. Social Science Research, 39(2), 285295. doi.org/10.1016/j.ssresearch.2009.07.006

Schlueter, E., Schmidt, P., \& Wagner, U. (2008). Disentangling the causal relations of perceived group threat and outgroup derogation: cross-national evidence from German and Russian panel surveys. European Sociological Review 24, 567581.Schneider, S., L. (2008). “Anti-immigrant attitudes in Europe: Outgroup size and perceived ethnic threat." European Sociological Review, 24(1), 53-67.

Schwartzburg, R. (2019, April 9). No, there isn't a White genocide. Jacobin. https://www.jacobinmag.com/2019/09/white-genocide-great-replacement- theory Semyonov, M., Raijman, R., Gorodzeisky, A. (2006). The rise of anti-foreigner sentiment in European societies, 1988-2000. American Sociological Review 71, 426-449. 
THE GREAT REPLACEMENT CONSPIRACY AND ANTI-MUSLIM RESENTMENT

Serwer, B. (2019). White nationalism's deep American roots. The Atlantic, 19. https://www.theatlantic.com/magazine/archive/2019/04/adam-serwer-madisongrant-white-nationalism/583258/

Stacey, M., Carbone-López, K., \& Rosenfeld, R. (2011). Demographic change and ethnically motivated crime: The impact of immigration on anti- Hispanic hate crime in the United States. Journal of Contemporary Criminal Justice 27(3) 278-298. doi: 10.1177/1043986211412560

Steinbuch, Y. (2019, August 1). FBI: Conspiracy theory 'extremists' are a terror threat. New York Post. https://nypost.com/2019/08/01/fbi-conspiracy-theory-extremistsare-a-terror-threat/

Steinmayr, A. (2018). "Contact matters: Exposure to refugees and voting for the farright." Working Paper.

Stephan, W. G., \& Stephan, C. W. (1993). Cognition and affect in stereotyping: Parallel interactive networks. In D. M. Mackie \& S. L. Hamilton (Eds.), Affect, cognition and stereotyping: Interactive processes on group perception (pp. 111-136): Academic Press.

Steyn, M. (2006, January 4). 'European population will be “40 percent Muslim”' by 2025', Wall Street Journal.

Steyn, M. (2005, November 8). 'Early skirmish in the Eurabian civil war', Daily Telegraph, https://www.telegraph.co.uk/comment/personal-view/3620861/Earlyskirmish-in-the-Eurabian-civil-war.html 
THE GREAT REPLACEMENT CONSPIRACY AND ANTI-MUSLIM RESENTMENT

Strabac, Z. (2011). "It's the eyes and not the size that matters" The real and perceived size of immigrant populations and anti-immigrant prejudice in Western Europe." European Societies, 13(4), 559-582. doi:10.1080/14616696.2010.550631.

Tarrant, B., H. (2019). The Great Replacement. https://imgprod.ilfoglio.it/userUpload/The_Great_Replacementconvertito.pdf

Tausch, N., Becker, J. C., Spears, R., Christ, O., Saab, R., Singh, P., \& Siddiqui, R. N. (2011). Explaining radical group behavior: Developing emotion and efficacy routes to normative and nonnormative collective action. Journal of Personality and Social Psychology, 101, 129-148. doi:10.1037/a002 2728

Torelli, C. J., Chiu, C. Y., Tam, K. P., Au, A. K., \& Keh, H. T. (2011). Exclusionary reactions to foreign cultures: Effects of simultaneous exposure to cultures in globalized space. Journal of Social Issues, 67(4), 716-742. doi: 10.1111/j.15404560.2011.01724.x.

Varadarajan, T. (2005, June 23). Prophet of decline, Wall Street Journal. https://www.wsj.com/articles/SB111948571453267105

Vertier, P., Viskanic, M \& Gamalerio. M. (2018). "Dismantling the 'jungle': Relocation and extreme voting in France," Sciences Po publications 110, Sciences Po.

Wilders, G. (2017). In Facebook, Geert Wilders. https://ptbr.facebook.com/geertwilders/videos/dear-friends-i-am-very/454543664943906/

Willer, R., Feinberg, M., \& Wetts, R. (2016). Threats to racial status promote Tea Party support among white Americans. Available from https://papers.ssrn.com/sol3/papers.cfm?abstract_id=2770186. 
THE GREAT REPLACEMENT CONSPIRACY AND ANTI-MUSLIM RESENTMENT

Williams, T., C. (2017, November 27). The French origins of "You will not replace us". The New Yorker. https://www.newyorker.com/magazine/2017/12/04/the-frenchorigins-of-you-will-not-replace-us 